\title{
doispontos:
}

\section{Marx, Engels e a antropologia: notas sobre uma relação subliminar}

\author{
Piero C. Leirner \\ pierolei@gmail.com \\ Departamento de Ciências Sociais, Universidade Federal de São Carlos (UFSCar), São Carlos, SP, Brasil
}

\begin{abstract}
Resumo: Este artigo trata de certas relações entre Marx/Engels e a antropologia, especialmente a vertente que ficou conhecida como estruturalista e alguns de seus desdobramentos. Para tal, em primeiro plano, analisa-se a relação entre Marx e Engels com Lewis Morgan, etnólogo norte-americano que serviu como base para várias notas dos dois sobre as então chamadas "sociedades antigas" ou "primitivas". Isso servirá como base para um primeiro esboço sobre o que podemos chamar de antropologia de Marx. Se, de um lado, essa linha em Marx foi obliterada por grande parte da antropologia que se iniciava no século XX, veremos, de outro lado, como o parentesco, desenvolvido a partir de Morgan, constituiu-se em um campo central para realizar uma passagem para apropriações posteriores, como o estruturalismo de Lévi-Strauss e todo um campo que se desenvolveu a partir dele em etnografias na Melanésia e Polinésia, por exemplo, na antropologia de Marshall Sahlins.
\end{abstract}

Palavras-chave: Antropologia; Marx; Engels; Morgan; Parentesco; Estruturalismo.

\section{Marx, Engels, and Anthropology: Notes on a subliminal relationship}

Abstract: This article deals with certain relations between Marx/Engels and Anthropology, especially the aspect known as structuralism and some of its developments. To this end, in the foreground, we analyzed the relation between Marx/Engels and Lewis Morgan, an American anthropologist who served as a basis for various notes of the first on the so-called "ancient societies" or "primitive man". This will serve as the basis for a first draft of what we might call Marx's anthropology. In contrast, in this line, Marx was obliterated by most of the Anthropology that began in the twentieth century; however, we will see how the kinship studies developed from Morgan constitute a central field to make a passage for further appropriations, such as the structuralism of Levi-Strauss and a whole field that has developed from it in Melanesia and Polynesia in ethnographies, such as the anthropology of Marshall Sahlins. Keywords: Anthropology, Marx, Engels, Morgan, Kinship, Structuralism.

\section{INTRODUÇÃO'}

O primeiro problema que poderia se impor a quem resolvesse pensar a relação que dá nome ao título deste artigo é seu evidente anacronismo: na época de Marx não se falava exatamente em antropologia, ou pelo menos não com o mesmo tipo de entendimento que ela passou a provocar a partir do começo do século XX. E, mesmo se quiséssemos traçar um recuo mostrando que as condições de formação dessa disciplina se davam em tempos anteriores - o que certamente é um truísmo - teríamos que realizar um extenso malabarismo, a partir de digressões por campos e influências complementares que o pensamento marxista realizou na antropologia em seu começo. Seria o caso de ver, como um dos poucos bons comentadores do tema coloca, como o que se fez na antropologia resultou em um quase-marxismo inglês, ou um 
cripto-marxismo americano (ALMEIDA, 2003, pp. 79-80); ou então, como procurarei argumentar, em um marx-subliminar na antropologia francesa, ou estruturalista, e no que foi influenciado por esta, sobretudo a partir de um extenso campo de estudos da Polinésia e Melanésia, que é tanto anglo-saxão como francês.

No entanto, é notável, de um lado, que a antropologia, especialmente a inglesa, só veio a tomar forma mais clara em relação às suas especificidades, especialmente como uma "ciência do mundo primitivo", tempos depois de Marx e ignorando sumariamente as poucas passagens que ele, junto com Engels, dedicaram às sociedades tribais, à organização do parentesco, ao problema da emergência do Estado antigo, e como tudo isso estava imbricado ao problema da produção dos meios de vida e da organização da propriedade. De outro lado, também podemos perceber que tais temas, desenvolvidos sobretudo a partir das notas que Marx realizou a partir da leitura da obra de um etnólogo norte-americano, Lewis H. Morgan, organizadas no volume "A Origem da Familia, da Propriedade Privada e do Estado", editado por Engels (1985 [1884]), vão repercutir na antropologia muito tempo depois e de forma indireta; isto, sobretudo, na antropologia francesa que se inspirou em Morgan, e numa norte-americana que se inspirou nesta francesa.

A ideia geral deste artigo é explorar, ainda que de maneira sumária, como um Marx ignorado e um Marx que aparece de forma indireta em certos clássicos da antropologia estão dialeticamente conectados, um é uma espécie de contrapartida do outro. Tentarei mostrar que se isso de um lado tem a ver, de maneira mais clara, com uma posição lateral que Morgan ocupava nos estudos etnológicos do século XIX - posição aliás que foi atestada com indignação por Engels - de outro lado acabou por se constituir num vetor de "influência inconsciente" nas teorias antropológicas que consagraram um certo legado de Morgan, especialmente aquelas que partiram do estruturalismo de Lévi-Strauss, a partir dos anos 1950.

Deste modo, o intuito aqui será o de mostrar, enfim, que Marx de alguma maneira esteve presente em certas teorias antropológicas, observando inclusive como certas dimensões que hoje poderíamos chamar de "antropológicas" do seu pensamento repercutem em discussões atuais. Seguindo este caminho, procurarei de um lado aproximar Marx de uma antropologia que "já estava" em seu pensamento; mas, de outro lado, procurarei, já alertando o leitor, me afastar das relações mais óbvias que uma "antropologia marxista", ou assumidamente marxista, realizou. Não tratarei, assim, de fazer um pout-purri sobre cada autor e perspectiva que declararam realizar uma antropologia de Marx, de propriedade de um pensamento marxista; pelo contrário, pensarei como de maneiras oblíquas certas perspectivas antropológicas de Marx (e Engels) se relacionaram a formas não próprias, anti-apropriações, sustentando uma razão dialética com o autor, ao mesmo tempo operada por identificações e contradições.

\section{ANTROPOLOGIA DE MARX E ENGELS}

Logo no início do prefácio à primeira edição da Origem... (1884), Engels chama a atenção para o fato de que Morgan teria descoberto, à sua maneira em Ancient Society (publicação de 1877), uma concepção materialista da história aplicada às sociedades pré-históricas, iletradas, isto é, ao pré-capitalismo. Se este, de fato, é um ponto a ser ressaltado, não encerra contudo o problema daquilo que este autor deixou no seu legado para uma antropologia do século XX, aquela que vai se nutrir das intuições deixadas em uma obra sua anterior (mas nem por isso menos importante), Systems of Consanguinity and Affinity in the Human Family, de 1871. Esta "inversão de prioridades", a obra posterior e mais genérica para Engels; a obra anterior e mais específica para a antropologia, seria um indício suficiente para enxergarmos a distância que a antropologia assumiu de Engels, e Marx, ao longo do tempo? Talvez sim, do ponto de vista de uma antropologia; mas não, do ponto de vista de Engels. No entanto, a partir da segunda edição das Origens, as coisas parecem adquirir um ar um pouco mais complexo, na medida em que Engels assume uma extensa defesa de Morgan 
em relação às criticas que seus colegas europeus lançaram à primeira obra. Neste momento, com a paisagem teórica se formando de maneira mais clara, é possível perceber em Engels ao mesmo tempo a defesa de um método que alia organização social às técnicas e incrementos materiais da vida (algo que fica mais claro em Ancient Society, que tem suas longas páginas resenhadas na Origem), e, paralelamente, anuncia a intrusão do parentesco como a modalidade de relação que viria a ser a chave privilegiada de entendimento da vida social.

Como se pode notar, é curioso que temos uma passagem em " $\mathrm{x}$ ": embora a grande teoria da história seja posterior em Morgan e, digamos, logicamente anterior em Engels, é depois deste perceber o debate que se realizou sobre o casamento e o parentesco com autores ingleses e alemães - especialmente John F. McLennan e Johann Bachofen, os maiores opositores a Morgan - que grande parte da teoria de Systems... vai ser acionada para entender passagens vitais na história humana: a relação entre o parentesco e a propriedade do trabalho; entre os laços de sangue e a propriedade da terra; entre as relações de afinidade e matrimônio e a propriedade privada, e finalmente as condições históricas em que todos esses elementos se imbricam com a emergência do Estado. Curiosamente, é essa discussão que já estava prenunciada em passagens esparsas na obra de Marx, especialmente naquilo que foi compilado depois como as Formações Econômicas Pré-Capitalistas, notas redigidas entre 1857-1858 que serviram como preparação a uma introdução à Contribuição à Crítica da Economia Política e ao Capital (Hobsbawn, em MARX, 1986, p. 13). No entanto, tal texto, publicado em Moscou apenas em 1939 como os Grundrisse, e na Alemanha em 1953, estava virtualmente desconhecido até então, e as notas de Marx assumidas na Origem... foram quem de fato deram o tom do pensamento de Marx sobre o "problema" das sociedades primitivas, que então estava sendo basicamente respaldado pelas teorias de Morgan.

É verdade que antes disso, especialmente n'A Ideologia Alemã (1845-6), algo já se prenunciava como um problema geral relativo à passagem de formas de propriedade comunais à propriedade privada capitalista; à passagem do campo à cidade; à passagem de uma forma de trabalho pleno ao trabalho alienado; ou, enfim, daquilo que alguns anos mais tarde seria a base da obra de Marcel Mauss, a discussão sobre a divisão entre uma economia da dádiva e outra do mercado, enunciando um dualismo histórico para o problema da reciprocidade (como veremos, será objeto de uma retomada por Lévi-Strauss, a partir das intuições de Morgan), que como se sabe ecoa Marx (ALMEIDA, 2003; GRAEBER e LANNA, 2005; LANNA, 2013; WEINER. 1992)². Mas não só: a Ideologia Alemã também esboça, na sua filosofia da história, algumas considerações sobre o problema da natureza, e as propriedades distintas do humano na atualização de um empreendimento único que é a efetuação de sua própria condição, como ser relacional e produtor de suas condições de existência.

Este não é um tema banal em Marx. Diria inclusive que é a condição de sua antropologia, pois assume em um "plano de imanência" (o de um "pré-conceito" em Marx, talvez) que a condição humana é, antes de mais nada, humana. Aliás, as relações humanas são humanas pois só os humanos se relacionam (MARX, ENGELS, 1984, p. 43); e o drama começa justamente quando "a própria ação do homem converte-se num poder estranho e a ele oposto, que o subjuga ao invés de ser por ele dominado” (idem, p. 47). Por isso, talvez, toda forma de idealismo deve ser refutada, na medida em que ambos enxergam aí uma manifestação (embora nada evidente) de uma forma apartada das propriedades reais que realizam a produção de si na história, isto é, as próprias relações (de produção, mas como produção e reprodução de si). Daí o trabalho entrar como uma chave para o entendimento da condições iniciais dessa produção, e da reprodução (e, assim, das condições de produção e reprodução do mundo, das relações, e, por fim, das classes). Este é um ponto que na filosofia de Marx pode ser entendido como uma chave para que nas Formações ele tente estabelecer uma saída para a tautologia de que "o homem produz o homem porque o faz como homem": "O objeto da produção, em si, é reproduzir o produtor em e simultaneamente com aquelas condições objetivas de sua 
existência” (MARX, 1986, p. 90). Fundamentalmente, lá vemos alguns elementos que tangem o problema antropológico de Marx, a passagem da natureza para a humanidade (cultura? Sociedade?).

Algumas passagens das Formações revelam estes passos. Permitam que mostre três delas, a fim de cotejarmos com elementos que aparecerão mais tarde em leituras essenciais para a antropologia. Vejamos:

"Pois, assim como o sujeito trabalhador é um indivíduo natural, um ser natural, da mesma forma a primeira condição objetiva de seu trabalho aparece como a natureza, a terra, como um corpo inorgânico. $\mathrm{O}$ próprio indivíduo não é apenas o corpo orgânico mas, ainda, esta natureza inorgânica como sujeito. Esta condição não é algo que ele tenha produzido, mas algo que encontrou a seu alcance, algo existente na natureza e que ele pressupõe" (MARX, 1986, p. 81).

Mais a frente:

"Em outras palavras: as condições originais de produção [a do escravo, do servo. n.a.] surgem como pré-requisitos naturais, como condições naturais de existência do produtor, do mesmo modo que seu corpo vivo, embora reproduzido e desenvolvido por ele, não é, originalmente, estabelecido por ele, surgindo, antes, como seu pré-requisito; seu próprio ser (físico) é um pressuposto natural não estabelecido por ele mesmo" (idem, p. 83).

E, finalmente,

"Assim, originalmente, propriedade significa nada mais do que a atitude do homem ao encarar suas condições naturais de produção como lhe pertencendo, como pré-requisitos de sua própria existência; sua atitude em relação a elas como pré-requisitos naturais de si mesmo, que constituiriam, assim, prolongamentos de seu próprio corpo". (idem, p. 85).

Evidentemente estaríamos diante de uma aporia caso a condição de "natureza" fosse vista como uma força transcendente na condição humana. Porém, creio que embora se abra uma fratura na dualidade "natural/social", ela não seja entendida como uma condição extrínseca ao humano, dada que ela é sobretudo natureza humana ("voltamos" a um campo de imanência?). De certa maneira, é este o ponto que permite a Marx seguir com a ideia de que a propriedade, isto é, a propriedade do corpo como trabalho, e da terra como matéria a ser convertida por trabalho humano, ou ela mesma como "corpo inorgânico", é a forma da realização das relações em que essa condição de apropriação da natureza se realiza. A terra é o trabalho dado; o corpo, o trabalho virtual; a propriedade, o trabalho atual; a relação social, o trabalho efetivo. Mas historicamente, em sua "condição inicial", a propriedade é o pertencimento a uma tribo. Pois trata-se ao mesmo tempo da posse comunal da terra, mas, também, da apropriação coletiva do corpo como, ao mesmo tempo, força de trabalho e relação de produção. É neste movimento que entendo que aparecem as convergências em relação à posterior obra de Morgan, pois, me parece, o parentesco vai entrar como condição destas relações ocorrerem neste mundo primitivo, isto é, o parentesco como uma relação de produção, ao mesmo tempo em que a produção é, enfim, reprodução ${ }^{3}$. Enfim, não só trabalhar é reproduzir, mas, me parece, naquele contexto, diferente da sociedade burguesa e da maneira como a família monogâmica descarta o trabalho feminino da esfera da produção (ENGELS, 1985, p. 80-81), reproduzir é trabalhar. ${ }^{4}$

Este ponto é particularmente ressaltado na defesa de Morgan que Engels assume; o parentesco, segundo ele, encontraria em Morgan um estatuto equivalente à evolução em Darwin ou a Mais-Valia em Marx (ENGELS, 1985, p. 17). É perceptível que a assim chamada pré-história teria seu motor acionado pelas relações de sangue da tribo e pela exogamia das gens, indexando dimensões políticas (o direito) e econômicas (a propriedade comunal), isto "em termos que podiam ter saído dos lábios de Karl Marx" (Idem, p. 19). De fato, a explicação para uma suposta passagem de estruturas sociais primitivas - por exemplo, as que apontam para uma coincidência sociológica entre federações iroquesas e as gens gregas (ainda que entre as primeiras e as segundas se identifique uma passagem entre o direito materno e o paterno [idem, p. 110]) - e uma economia política que supõe uma concentração da propriedade, é algo que está tanto em Morgan 
quanto em Marx, e para ambos isso é visto como um sinal de decadência das primeiras sociedades em função de guerras, saques e antagonismos políticos (idem, pp. 106-109). ${ }^{5}$

Neste ponto, inclusive, Marx já chamava a atenção para o fato de que a condição interna de desagregação da propriedade comunal vem do fato que ela é essencialmente guerreira: "A guerra é, portanto, a grande tarefa que a todos compete, o grande trabalho comunal, e se faz necessária, seja para a ocupação das condições objetivas da existência, seja para a proteção e perpetuação de tal ocupação. A comunidade integrada por grupos de parentesco, é, pois, em primeira instância, organizada militarmente como força guerreira militar, e esta é uma das condições de sua existência como proprietária" (MARX, 1986, p. 69). E, assim, "Na medida em que se acentua a atuação destes fatores, e quanto mais cresce a tendência de se definir o caráter comunal da tribo - enquanto unidade negativa contra o mundo exterior - mais se impõem as condições que permitirão ao indivíduo tornar-se proprietário privado de um lote definido de terra, cujo cultivo corresponderá somente a ele e à sua família" (Idem, p. 70). ${ }^{6}$

Este passo histórico, que nas Formações também é objeto de análise de três versões diferentes - a selvagem, a grega/romana e a medieval -, aponta para um elemento fundamental, tanto nas visões de Morgan quanto de Marx e Engels, que é a separação entre os planos doméstico e político, a sincronização entre o aparecimento da propriedade privada e o surgimento de um protoplasma de Estado. No entanto, as diferenças ainda podem ser explicadas nessa passagem de Hobsbawn: "Não se trata, inteiramente, de uma comunidade igualitária, pois o desenvolvimento tribal, juntamente com os casamentos intergrupais e as conquistas, já tende a produzir grupos de parentesco socialmente mais elevados do que outros, embora o cidadão romano seja, essencialmente, um proprietário de terras, 'mantendo-se a comuna com a reprodução de todos os seus membros como camponeses autossuficientes, cujo tempo excedente pertence à comuna, para atender a fins comunais, como a guerra etc.' (p. 71)" (citado em MARX, 1986, p. 40; grifos meus).

Tal ponto, esse que define um "parentesco mais elevado" em antagonismo a um mais primitivo, foi entendido por Morgan como a separação entre "sistemas classificatórios" e "sistemas descritivos" (MORGAN, 1871). Em essência, trata-se, respectivamente, de sistemas que se definem por uma equalização entre parentes lineares e colaterais (por exemplo, onde terminologicamente "pai" e "irmão do pai" são os "mesmos"), e como resultado o sistema de parentesco se baseia sobretudo em casamentos endogâmicos; e sistemas onde tais posições são terminologicamente distintas, e portanto o parentesco tem que se realizar sobretudo a partir da exogamia, e assim com uma aliança em relação a grupos externos. Isso quer dizer, enfim, nos termos tanto de Morgan quanto de Marx e Engels, que este "parentesco superior" exige sobretudo a instituição de uma modalidade de relação política, que transborda as relações de sangue. Nesse ponto, ainda que Engels assuma a tarefa de descrever as condições econômicas que são explicadas por Morgan como transformações das condições formais entre uma associação familiar e outra política (ENGELS, 1985, p. 120), é notável que estão aí as bases para se pensar dois dos termos que vão marcar também uma dimensão profunda que a antropologia deu à análise de sistemas de parentesco. ${ }^{7}$ São eles, juntos com seus correlatos, consanguinidade::parentesco/afinidade::política.

Neste ponto, o desmembramento entre o doméstico e do político terá repercussões estruturais na história da antropologia, e como ela apropriou-se de Marx, e de Morgan. Vejamos então esse passo.

\section{ANTROPOLOGIA CONTRA E COM MARX E ENGELS}

Engels já mostrava, no calor da hora, a péssima recepção que o trabalho de Morgan teve na Inglaterra (1985, p. 18). Talvez o que ele não imaginaria é que isto ainda iria durar muito. Como mostra Márcio Silva (2010, p. 323), comentando Morgan, "Meyer Fortes conta uma história engraçada de seus tempos 
de estudante de antropologia na London School of Economics. Diz que a primeira vez que ouviu falar de Morgan foi em 1931, nos seminários do Professor Malinowski ${ }^{8}$, que o apresentava como um 'falso profeta', a 'personificação do Reino do Erro na antropologia que o funcionalismo veio derrotar' e um 'exemplo lamentável de gênio enganador'. O carismático argonauta de nossa disciplina dizia também a seus jovens estudantes que Rivers [antropólogo britânico que levou a fundo o problema das terminologias de parentesco levantado por Morgan] era a 'besta negra' atrás da qual o espectro de Morgan ressurgia como 'inspirador da enganosa ênfase causal das formas de casamento nas instituições do parentesco'. Fortes conclui: 'Morgan era para mim - e, suspeito, para todos os alunos de Malinowski - um dos principais anti-heróis de nossa disciplina'. Mas não só Malinowski reservava esse lugar para Morgan. Aparentemente, todos autores que fizeram com que a teoria da descendência fosse o ramo triunfante da antropologia até os anos 1950 também trataram dessa questão, geralmente sob a rubrica de uma crítica ao 'método da história conjectural' utilizado por este".

Talvez seja preciso entender um aspecto que me parece central neste "método" (claro que Morgan não reconheceria a alcunha "conjectural"...). Um dos elementos que mobilizou toda a problemática de Systems of Consanguinity and Affinity... foi um dado que surpreendeu Morgan: a notável similaridade entre terminologias de parentesco encontradas entre os sêneca-iroqueses com os quais ele conviveu nos EUA, e outras encontradas no sul da Índia entre os povos falantes de variações de uma língua dravidiana. Com certas aproximações e comparações com terminologias coletadas na Polinésia e Austrália, Morgan foi levado a pensar numa suposta origem asiática do homem americano. Pertinente ou não, foi essa intuição inicial que provocou em Morgan um movimento para estabelecer a relação entre parentesco e sociologia que nos parece ter chamado a atenção em Marx e Engels. Ainda que não seja possível implicar Morgan numa certa sonegação de nossos filósofos alemães por parte desta antropologia, é notável que a proximidade metodológica dos três parece ter provocado sua obliteração pela parte vencedora da antropologia de então. Ou seja, se há um ponto em que os antropólogos parecem discordar do modo pelo qual Morgan e Marx/Engels se aproximam, é o método, fundado em convergências históricas, e não sociológicas.

Curiosamente, tal tipo de rejeição ganhou uma força para além das implicações que uma análise fria das inconsistências teóricas poderiam supor. Ela se espalhava para outros lugares. Franz Boas, etnólogo alemão radicado nos Estados Unidos, também se voltou contra Morgan, desprezando toda a sociologia do parentesco em nome de uma defesa da autonomia histórica local. Mas não só. Foi sobretudo a frente britânica, que começa a despontar nos anos 1920 com toda uma (importante) concepção metodológica que se voltava contra as conjecturas históricas, supondo acima de tudo uma certa relatividade de cada sistema social, mas, também, uma auto-funcionalidade dos sistemas sociais que despreza qualquer ligação orgânica entre entidades separadas geograficamente, que pretende sepultar Morgan (e os de sua geração), por conta de seu método. Uns mais (Malinowski), outros menos (Radcliffe-Brown), acabam indexando a sociologia de Morgan (parentesco) ao método dele (evolucionismo); mas, de todo jeito, naquela época a perda parecia ser (quase) total.

Assim, o parentesco, como grande domínio da antropologia da primeira metade do século XX, parecia ter encontrado seu fundamento muito mais em Durkheim, do que em Morgan/Marx. Mesmo as influências mais notáveis de Morgan, como o antropólogo neo-evolucionista Leslie White, mais enveredaram por uma antropologia das técnicas e das culturas materiais, encarnando inclusive um certo marxismo vulgar, do que propriamente investiram numa continuidade para as chaves teóricas suscitadas pelos problemas do parentesco. Marx, assim, desapareceu das antropologias centrais até os anos 1950, dando lugar a outros autores, especialmente Durkheim - seja aquele da Divisão do Trabalho Social, aplicado por toda uma antropologia afeta à morfologia social (Radcliffe-Brown e a teoria da descendência, acima mencionada); 
seja aquele do Suicídio, e o método estatístico recolocado por Malinowski e seus discípulos. Mas também Weber, Talcott Parsons, ou a psicologia social de W. Wundt. Deste modo, é preciso inclusive levantar a suspeita, embora não tenha fôlego para tratar disso aqui, se de fato Morgan mais "atrapalhou" do que "ajudou" uma bem sucedida agregação do pensamento marxista na antropologia. Mas, claro, isso se fosse aqui tomar essa relação de modo imediato e mecânico, o que não é o caso.

Pois, de outro lado, Morgan, e Marx, serão ressuscitados de modo bem peculiar justamente a partir de uma teoria que vem ser a rival dos paladinos de Durkheim no mundo anglo-saxão, e possivelmente a mais bem sucedida do século XX: o assim chamado estruturalismo, desenvolvido primeiramente na teoria da aliança nas Estruturas Elementares do Parentesco, tese de doutorado de C. Lévi-Strauss publicada em 1949 (1982), que, por sinal, é dedicada a Morgan..$^{10}$ Entre outras coisas, o que se pode ler a partir desta obra é um deslocamento da ênfase das relações de parentesco baseadas na consanguinidade para aquelas baseadas na afinidade como foco primordial de constituição da vida social. Ou seja, de maneira muito resumida e talvez um pouco grosseira, a ideia é que se entenda o fundamento da vida social a partir das alianças que são estabelecidas em relações de matrimônio, e não mais nas relações de descendência e filiação (consanguinidade), como pressupunham os ingleses. Um dos pontos pelos quais Lévi-Strauss assume a defesa desta proposição está na passagem entre inúmeros regimes de matrimônio e organização social como respostas probabilísticas ao modo pelo qual se pode estabelecer um cálculo na reciprocidade em diferentes sociedades. E, tenho a impressão que este é um elemento claramente inspirado em Morgan, não só pela dualidade entre sistemas de consanguinidade e afinidade, mas também por conta de realizar uma aproximação entre sistemas geograficamente distantes, entendendo eles como sendo uma cadeia de transformações, um do (e para) o(s) outro(s).

Este é um ponto delicado, pois de um lado não se pode pensar tais transformações como "históricas"; mas nem por isso se pode deixar de pensa-las como "estruturais", e nesse sentido há um claro apelo à noção de modelo suscitada pela obra de Marx. Como ele mesmo coloca, "Se admitirmos, na própria linha de pensamento de Marx, que as infraestruturas e as superestruturas comportam múltiplos níveis, e que há vários tipos de transformação para passar de um nível a outro, será também concebível a possibilidade, em última análise e abstraindo-se os conteúdos, de caracterizar diversos tipos de sociedade por leis de transformação: fórmulas indicando o número, a potência, o sentido e a ordem das torções que seria preciso anular, por assim dizer, para reencontrar uma relação de homologia ideal (logicamente, não moralmente) entre os diversos níveis estruturados." (LÉVI-STRAUSS, 2008 [1958], p. 359). Este é um lado que vai ficando cada vez mais claro no prosseguimento da obra de Lévi-Strauss. Ele não só admite em várias ocasiões que Marx foi sua grande influência (com outras, como Freud, a geologia... cf. ERIBON e LÉVI-STRAUSS, 1990, p. 140), como parece que a dialética parece desempenhar o motor de noções centrais para se entender as transformações de séries mitológicas, como por exemplo a de "grupo de transformação".

Tal ponto me parece particularmente claro em uma passagem do texto "As Descontinuidades Culturais e o Desenvolvimento Econômico" (LÉVI-STRAUSS, 1989 [1973]), nas quais dois elementos podem ser ressaltados: o primeiro é a noção de que o mundo primitivo carrega um protoplasma da civilização ocidental, e por isso "a industrialização não é um fenômeno autônomo e que se procura introduzir, de fora, em civilizações que permaneceram na passividade. Ao contrário, a industrialização é uma função, e um resultado indireto, da condição das sociedades ditas primitivas..." (idem, p. 319). ${ }^{12}$ Nesse sentido, Lévi-Strauss conecta a este comentário o segundo elemento, que entendo ser resultado deste "modelo (auto)transformacional": "O problema fundamental do marxismo é saber porque e como o trabalho produz uma mais-valia. Ainda não foi suficientemente notado que a resposta de Marx a este problema tem um caráter etnográfico" (idem, ibid.). Este elemento se conecta a dois argumentos, em Marx: o primeiro, 
é de que a relação entre mais-valia e trabalho seria uma propriedade da cultura ("tal como os etnólogos a entendem...”); o segundo, é que o gasto do sobre-trabalho para outro é uma condição imposta à força. Daí, segundo Lévi-Strauss, o capitalismo ser apenas uma espécie de continuidade, lógica e histórica, da relação entre colonizador e colonizado, e por isso talvez "a ciência econômica e a sociologia nascem como dependentes da Etnografia" (idem, ibid.) ${ }^{13}$.

No entanto, é preciso ter em mente que este Marx vai aparecer, ele mesmo, apenas de maneira subliminar na teoria levistraussiana. Isto porque não deixa de ser claro que há uma torção na superfície que abriga as contradições do humano. Para Lévi-Strauss," O marxismo, senão o próprio Marx, raciocinou muitas vezes como se as práticas decorressem imediatamente da práxis. Sem colocar em questão o incontestável primado das infraestruturas, acreditamos que entre práxis e práticas sempre se intercala um mediador, que é o esquema conceitual por obra do qual uma matéria e uma forma, uma e outra desprovidas de existência independente, realizam-se como estruturas, isto é, como seres ao mesmo tempo empíricos e inteligíveis. E, com esta teoria das superestruturas apenas esboçada por Marx que desejamos contribuir, reservando à história -assistida pela demografia, pela tecnologia, pela geografia histórica e pela etnografia - o cuidado de desenvolver o estudo das infraestruturas propriamente ditas, que não pode ser principalmente a nossa, pois a etnologia é, antes de tudo, uma psicologia." (2008b [1962b], pp. 149-150).

Esta sutil, mas notável inversão proposta por Lévi-Strauss tem implicações importantes para a antropologia. Se Morgan constituiu um ponto de partida nas Estruturas Elementares..., e no meio do caminho a intuição que melhor sobreviveu na relação que Lévi-Strauss aponta com suas influências foi aquela que juntou a dialética como método e o parentesco como problema a ser resolvido, podemos dizer que um ponto de chegada é uma inversão dos parâmetros que iluminam o lugar desses objetos na teoria: agora, especialmente depois da década de 1960, nos parece que tanto em Lévi-Strauss quanto em toda uma série de autores que vão radicalizar a teoria da aliança se procurará chegar a um lugar de síntese entre cosmologia e sociologia; entre mitologia e prática; entre a metáfora e a história. É nessa chave que pretendo concluir este texto, mostrando como este Marx subliminar reaparece na antropologia, apontando mais para uma leitura criativa que se pode fazer dele, do que propriamente uma apropriação imediata como a que ocorreu em várias tentativas de se estabelecer um tipo de antropologia marxista (vulgar).

\section{ANTROPOLOGIA E MARX E ENGELS}

Seria impossível na dimensão de um artigo mapear todos autores e tendências que trabalharam tanto sob um viés marxista quanto com usos de conceitos marxistas. Marx provocou desde usos mecânicos, em correntes de uma certa antropologia econômica nos anos 1960/1970 ${ }^{14}$, até uma recolocação de problemas inicialmente propostos por Lévi-Strauss para o pensamento ameríndio ${ }^{15}$. Para concluir este texto, gostaria de mencionar especialmente um autor que mostra não só que Marx está vivo na antropologia, mas que a antropologia de Marx está ativa numa antropologia não necessariamente marxista. Trata-se de Marshall Sahlins, através de quem podemos ver em múltiplos níveis como Marx entrou no pensamento antropológico, subliminarmente inclusive, com um encontro entre o estruturalismo e o marxismo na antropologia. Mas como se deu isso?

Sahlins é um antropólogo norte-americano, nascido em 1930, e formado inicialmente em Michigan, onde estudou com Leslie White, um dos principais defensores da teoria de Morgan tendo levado a cabo sobretudo uma visão diacrônica da história determinada por mudanças tecnológicas. White primou sobretudo por encampar uma teoria de Morgan endossada por Engels, o que de certa maneira teria inclusive repercutido em uma visita sua à União Soviética, em 1929, e sua adesão ao partido socialista americano. Como se sabe, 
toda uma linha de antropólogos que ecoaram essa tendência, devido ao forte clima anticomunista que imperava nos EUA, se colocaram sob o guarda-chuva deste materialismo disfarçado no neoevolucionismo, ou cripto-marxismo, conforme sugeriu M. Almeida (2003). Sahlins não foi exceção.

Em meados da década de 1950, ele realizou um estudo que viria a ser seu doutorado, Social Stratification in Polynesia (Sahlins, 1958), onde analisaria 14 sociedades diferentes nessa macrorregião, tentando compor uma correspondência entre a mobilização material das forças produtivas e as diferenças sociopolíticas que ali não eram nada desprezíveis: tratavam-se de paisagens etnográficas que compreendiam desde esquemas igualitários e com uma economia fortemente redistributiva, até estruturas burocráticas com hierarquias administrativas que impunham um complexo sistema de divisão de trabalho e distribuição desigual dos produtos do trabalho. No entanto, ao confrontar essas diferenças com aquele problema central posto pela antropologia de Marx - a produção de si como o quantum de esforço ou trabalho social realizado para reproduzir as próprias condições de vida - é que um notável desdobramento no pensamento deste autor começa a acontecer.

O grande problema, que começa a repercutir nos textos de Sahlins do começo da década de 1960 (incluindo-se aí o seminal Poor Man, Rich Man, Big Man, Chief; Political Types in Melanesia and Polynesia, de 1963), é que, em primeiro lugar, o esforço social total para realizar a vida em tais sociedades divergia muito pouco (e nisso se considerava o conjunto do trabalho empreendido para reproduzir a sociedade, do trabalho de pesca e agricultura ao preparo dos meios de produção; da construção de casas ao trabalho doméstico, etc.); isto é, as diferenças sociopolíticas aparentemente apontavam para determinações de outras ordens que aquelas estritamente vinculadas à reprodução das condições materiais de existência. Em segundo lugar, e cotejando esses dados com os de outros antropólogos que realizaram pesquisas semelhantes em lugares extremamente áridos - com Bosquímanos na África do Sul, com habitantes do deserto australiano - é que Sahlins começa a formular uma noção alternativa ao problema do equacionamento entre meios de produção "rudimentares" e uma suposta escassez que seria marca registrada do mundo primitivo. Começava a cair por terra a noção de que a técnica e a abundância eram elementos necessariamente convergentes.

O que Sahlins percebeu foi justamente o contrário. Na maioria das sociedades chamadas primitivas, o quantum de trabalho social necessário para a reprodução das próprias condições de existência era significativamente menor que as então 55 horas médias de trabalho que os europeus de então tinham que realizar toda semana. Tratava-se, muitas vezes, de sociedades que se dispunham a trabalhar de 3 a 5 horas diárias, de 3 a quatro dias por semana. Se a escassez e a desgraça primitiva fossem realmente patentes, como responder, portanto, à simples questão do por que não se trabalhava mais em tais sociedades? Além disso, seria o caso de se entender também, a reboque, o papel que o excedente de produção realizava em tais contextos, já que, diferentemente das sociedades capitalistas, a reprodução das próprias condições de produção não supunha toda a engrenagem de extração da mais-valia, e a consequente reprodução do capital, em seus ciclos restrito e ampliado (cf. Marx, O Capital, livro I). Enfim, a conclusão a que Sahlins logo depois chegaria é que tais sociedades eram, acima de tudo, "as Primeiras Sociedades de Afluência" (SAHLINS, 1968).

Mas então, afinal, o que se fazia com o tempo não trabalhado "na reprodução material"? Este é um ponto complexo, para o qual não poderei retomar toda a argumentação. No entanto, cabe chamar a atenção para dois pontos principais: em primeiro, que Sahlins começa a formular uma noção que pretenderia a dar conta de outros "focos de produção" nas sociedades primitivas, especialmente aqueles que estariam de alguma maneira entrelaçados à cosmologia e ao parentesco; em segundo, novamente seria o caso de então explicar como isso estaria conectado às variações sociopolíticas das realidades inicialmente tomadas como exemplos empíricos a serem explicados, como o Havaí e certas regiões da Melanésia. 
Ambos os pontos parecem estar profundamente ligados, e uma decorrência disso é uma aproximação inicial que Sahlins vai realizar com a literatura francesa, especialmente Mauss e Lévi-Strauss. E isso também ocorre "de fato", uma vez que numa espécie de autoexílio provocado em protesto com relação à guerra do Vietnã, Sahlins justamente vai trabalhar no Laboratório de Antropologia Social, dirigido por Lévi-Strauss, entre 1967 e 1969. De maneira muito sintética, tais aproximações forçaram a análise econômica sobre a reprodução social em primeiro lugar a ser pensada em função do problema da reciprocidade e da redistribuição de bens; em segundo lugar, o modo que isso se dá, em diferentes contextos, está enquadrado por esquemas cosmológicos previamente estabelecidos, fazendo com que aquilo que previamente tomamos como a "infraestrutura" seja constantemente alterada por uma cosmologia que prescreve um modus operandi para as relações sociais. Ou seja, não seria o caso de se pensar que tanto as dimensões materiais quanto as simbólicas poderiam ser colocadas como "infraestruturais? Parece que este é o caso quando se trata de sociedades que não operam radicalmente a divisão entre sujeito e objeto, ou entre as determinações subjetivas e objetivas, se assim for mais convenientemente colocado (veremos melhor isso ao final).

Por exemplo, no Havaí o esquema adveio de uma divisão fundante da sociedade, entre uma classe de chefes que era tomada como estrangeira mas com poderes redistributivos sobre a terra (poderes divinos, como o da fertilidade, mas também de controle burocrático e uma divisão do acesso aos produtos e meios de produção), e de uma população nativa local que produzia vários bens, mas, sobretudo, mulheres que se incorporariam em linhagens superiores em um extenso projeto de ascensão social pela via do "amor" (cf. SAHLINS, 1985). Mulheres, bens e poder político eram parte de uma mesma engrenagem, cuja cosmologia oferecia uma moldura inicial (idem, ibid.). De certa maneira, realiza-se aqui de maneira híbrida, o projeto de Lévi-Strauss de fazer uma leitura "multi-níveis" a partir da superestrutura e de levar em conta a condição inicial de uma antropologia de Marx, aquela que entende que, afinal, o "homem produz a história com seus próprios meios, mas sem necessariamente sabê-lo"16.

Para se ter uma ideia do tipo de desdobramento que as análises de Sahlins provocaram nessas interconexões entre estruturalismo e marxismo, podemos inclusive pensar em exemplos contraditórios para análises que ele empreendeu inicialmente para a Melanésia (Sahlins,1963). Na elaboração de uma espécie de "tipo ideal" melanésio, a figura do "big-men", um sujeito cujo prestígio depende sobretudo da capacidade de agenciar uma complexa forma de redistribuição de bens, dependente de uma igual capacidade de captar esposas que produzam-nos, foi central em análises que se espalharam em situações mais próximas, em áreas etnográficas contínuas (por exemplo, os textos editados por Godelier \& Strathern, 1994), quanto em análises mais distantes, como a conhecida formulação anti-marxista elaborada por Pierre Clastres, aluno de Lévi-Strauss e colaborador de Sahlins, ao tratar um material sul-americano que tocava o problema da guerra nas sociedades primitivas.

Neste último caso, Clastres (1980) vai pensar a condição fragmentada e autônoma de vários grupos das terras baixas sul-americanas a partir da noção de autarquia que Sahlins desenvolveu sobre o material melanésio, isto é, com uma tendência daquelas sociedades em não alienarem sua condição política num processo de troca que dependeria de um poder exterior. Para Sahlins (1963), a falência do sistema de "big-men" acontece justamente quando este resolve expandir o sistema de trocas para além da parentela mais próxima ou do grupo local, provocando um processo de alienação do bem produzido que levaria ao colapso das relações internas de produção - justamente aquelas que realizam primeiramente o esquema de trocas e reafirmam o prestígio político desse articulador. Clastres mostra isso justamente como parte de um processo de divisão da sociedade primitiva, que dependeria antes de uma etapa política que econômica. A emergência de uma política exterior é que produziria o bem alienável, e portanto é só a partir daí que ocorreria algo como a divisão em "classes". Trocando em miúdos, para Clastres, e contra Marx, esse (proto) Estado produz as classes, e não o inverso. 
De outro lado, é notável que a análise do "big-men" re-equacionou uma série de problemas anteriormente colocados por Marx. As análises de Sahlins e Lévi-Strauss, por exemplo, colocadas no contexto das Ilhas Trobriand (N. Guiné), inspiraram autores como Anette Weiner e Maurice Godelier a pensar em termos do problema da alienação os paradoxos de bens que engendram o movimento "keep-while-giving" (WEINER, 1992; GODELIER, 1996). ${ }^{17}$ Mas, certamente, a análise que mais rendeu frutos desta discussão foi aquela empregada por Marlyn Strathern (1988), para o caso das terras altas da Nova Guiné, onde o "trabalho não pode ser medido separadamente das relações sociais” (p. 160), e assim objetos tanto criam como separam relações. A objetificação, que para Marx tem como condição a separação entre sujeito e objeto, parece na Melanésia ser alvo também da personificação. Para ser objeto, é preciso antes de mais nada ser um sujeito, e um sujeito capaz de se eliciar de si, nos outros e nos objetos que também constituem as relações (id., pp. 176 e ss.). Nesse caso, o gênero, que para Lévi-Strauss, em As Estruturas Elementares... assumiu marcadamente a divisão sujeito:objeto: homens:mulheres, em Strathern, recolocando o problema a partir de Marx (e de outros melaneseístas), mas invertendo-o, vai ser tomado como produto, mas como um produto inseparável, ou inalienável das próprias condições de produção da vida social. As relações, assim, são elas próprias meios de produção, e assim o parentesco volta-se a uma reconciliação com as condições inicialmente pensadas na antropologia de Marx, penso eu.

Afinal, o que se passou com Marx aqui? De certa maneira, vejo que ele precisou ser recolocado, junto com uma discussão que vinha do problema da reciprocidade a partir das trocas, e destas recolocando o problema dos bens em termos de uma problemática de gênero, vis-à-vis com teorias nativas que de um lado confrontam certos pressupostos do modo de produção capitalista; mas, de outro, recolocam o problema da natureza da propriedade tal como foi pensado nos termos das formações pré-capitalistas, nos textos de Marx e Engels, e nas suas apropriações de Morgan. De outro lado, muito que se pensou a respeito da natureza hierárquica e do poder político em sociedades primitivas procurou inverter Marx; no entanto, ele continua lá, e em certo sentido é preciso reconhecer que suas conexões apontam para o caminho, embora a direção seja outra.

Evidentemente estas são exposições muito sumárias, mas que desejam sobretudo chamar a atenção para o fato de que Marx, ao contrário do que se poderia pesar através de críticas rasas, teria sido negado por essa gigante inflexão que foi o estruturalismo na teoria antropológica. Tais críticas colocam, entre outras coisas, que o estruturalismo obliterou a história, o sujeito e a agência da análise. O objetivo central deste artigo é mostrar justamente o contrário: que o aspecto dialético, e talvez subliminar, de Marx em análises que poderíamos chamar de "algo estruturalistas", vem mostrar que nem a antropologia de Marx foi sonegada, nem Marx foi corrompido pela antropologia. Em todo caso, é preciso alertar o leitor que em antropologia ainda se lê muito pouco Marx; e, quando o fazemos, geralmente é através de Sahlins e dos etnólogos da Melanésia. Seria o caso, então, de pensar em novamente voltarmos para uma leitura, inclusive pensando como a antropologia poderia retomar Marx numa leitura do capitalismo. Fica, assim a sugestão para intensificar esse diálogo.

\section{NOTAS}

1. Gostaria de agradecer aos organizadores deste número de Doispontos, bem como ao parecerista que colocou sugestões muito interessantes. Toda a responsabilidade sobre o que está escrito, no entanto, é minha.

2. Tal ponto, aliás, também é particularmente desenvolvido em uma crítica a Marx a partir de Mauss retomada por Agamben (2012 [1977], pp. 83-4), para quem o dom e o potlach analisados pelo segundo desmente toda uma visada 
utilitarista do pensamento marxista; algo que já podia ser visto anteriormente também em Bataille, por exemplo em “A noção de dispêndio", de 1933 [aqui visto a partir da edição brasileira de 2013).

3. E, na sociedade primitiva, essa é a condição básica da "propriedade de si": "Propriedade — e isto se aplica às suas formas asiática, eslava, antiga clássica e germânica — originalmente significa uma relação do sujeito atuante (produtor) (ou um sujeito que reproduz a si mesmo) com as condições de sua produção ou reprodução como suas, próprias" (MARX, 1986, p. 90).

4. Como veremos à frente, na antropologia, sobretudo da Melanésia, a produção de pessoas e de coisas só pode ser vista como um contínuo. Produzir através do sexo ou do trabalho são tarefas da mesma ordem, e, portanto, o gênero é aplicável às pessoas e às coisas (STRATHERN,1988).

5. Aliás, esta ideia parece ter ressonância numa certa predileção socialista de Morgan, também ressaltada por Engels (op.cit., p. 17; ver também ALMEIDA, 2003).

6. Como veremos à frente, a condição exterior e a autonomia tribal foram um ponto fundante na oposição entre sociedades hierárquicas e igualitárias; este foi um ponto explorado nas Formações..., e levado à frente pela antropologia.

7. Além disso, haveria aí, de acordo com Engels, paradoxalmente as raízes da causa de uma decadência humana (apesar do quadro de evolução subjacente à história), que seria o deslocamento da mulher do papel de produção social e a armação das condições necessárias para o aparecimento de uma família monogâmica burguesa (idem, pp. 80-81), pela qual nunca antes se viu tamanha concentração da propriedade e do poder político.

8. B. Malinowski, figura centralizadora da antropologia britânica do começo do século XX, é conhecido como um dos inventores do método etnográfico, com a longa permanência em campo e a reflexividade da posição de observador nos dados de pesquisa. Vale lembrar apenas que antes dele, ainda no século XIX, Morgan conviveu longos períodos entre os Sêneca-iroqueses.

9. Apenas como nota, vale mencionar que o herói sociológico desta geração da antropologia britânica era certamente Durkheim. Mesmo se especularmos a aproximação que Malinowski faz a Marx numa “teoria das necessidades", é patente que os problemas mais fundamentais do parentesco foram tratados por aquele como uma espécie de "falsa álgebra” (MALINOWSKI, 1930). Some-se a isso todo um investimento deste em uma metodologia etnográfica, com o resultado das observações condicionados pela relação que se estabelecia com os observados, e se entende porque uma perspectiva focada numa aproximação entre grandes instituições humanas era vista com reservas.

10. E, claro, sem mencionar que as Estruturas... vêm de um pensamento francês; seu título é uma citação da Formas Elementares de Vida Religiosa, de Durkheim; várias de suas passagens são um decalque da arquitetura deste livro; mas, de fato, é um livro que vai recolocar Freud numa discussão que Durkheim procurou desqualificar este. Além disso, em obras posteriores, Lévi-Strauss vai constantemente sabotar conclusões de Durkheim, como por exemplo no Totemismo Hoje (1962).

11. Como coloca M. Almeida, "As propriedades que caracterizam a mente humana são invariantes ao longo das transformações que levam de uma sociedade a outra. Tais transformações são reversíveis e nos conservam no domínio do humano, e nessa medida constituem um grupo. Não há origem, nem sentido, nem escala privilegiada para a humanidade. A natureza humana radica, por assim dizer, num grupo de transformações .” (1999, p. 175). Em certo sentido, a pressuposição da ideia de grupo de transformação é que essas estruturas comunicam-se entre si, e, quem sabe, jogando em um outro quadro conceitual, não seriam elas próprias variações de um "campo de imanência"? Quem sabe em um sentido homólogo ao que Marx pensou a própria ideia de natureza humana?

12. Chama a atenção como este é um argumento que Marshall Sahlins vai usar em sua teoria da história havaiana, algum tempo depois (veremos este autor à frente). 
13. E como bem apontou um parecerista anônimo deste artigo, esta precedência da força sobre a economia será uma das teses que Clastres sustentará contra uma antropologia marxista.

14. Ver, por exemplo, Meilassoux, 1964; Sobre um certo marxismo francês e seus desdobramentos no Brasil, ver Viveiros de Castro, 1999; sobre o marxismo e a antropologia em geral, ver o texto de Almeida, 2003.

15. Para citar apenas dois exemplos mais recentes, ver a ótima apropriação que Carlos Fausto (2001) faz do conceito de "Consumo Produtivo" de Marx. Também a ideia de Terry Turner (2009) de como nos mitos ameríndios o problema da distinção natureza/cultura também envolve uma questão com a categoria "trabalho".

16. É preciso ter em mente que Sahlins não rejeita Marx, mas rejeita uma razão utilitária que se vinculou ao seu pensamento. Para ter uma clara noção desses limites, ver seu livro de 1976, Culture and Practical Reason.

17. Tratam-se de bens inalienáveis: bens sagrados, ou, em contextos hierárquicos, que supõem certo valor que os prendem a seu "dono". Isso se dá de maneira particularmente intrincada quando se pensa na "troca de mulheres", para qual Weiner fará uma discussão sobre bens masculinos e femininos, seguindo a trilha colocada por M. Strathern (ver adiante).

\section{REFERÊNCIAS BIBLIOGRÁFICAS}

AGAMBEM, Giorgio. 2012 [1977]. Estâncias - a palavra e o fantasma na cultura ocidental. Belo Horizonte: Editora UFMG. [Stanze. La parola e il fantasma nella cultura occidentale. Torino: Einaldi].

ALMEIDA, Mauro W. B. 1999. "Simetria e Entropia: sobre a noção de estrutura de Lévi-Strauss". Revista de Antropologia. 42(1). São Paulo: USP.

2003. "Marxismo e Antropologia". In Armando Boito Jr. e Caio N. de Toledo (orgs.) Marxismo e Ciências Humanas. São Paulo, Xamã/FAPESP/CEMARX, 2003, pp. 75-85.

BATAILLE, Georges. 2013. A parte maldita, precedida de "A noção de dispêndio". Belo Horizonte: Autêntica.

CLASTRES, Pierre. 1980. Arqueologia da Violência. São Paulo: Brasiliense.

Engels, Friedrich. 1985. A Origem da familia, da Propriedade Privada e do Estado. Rio de Janeiro: Editora Civilização Brasileira.

ERIBON, Didier e LÉVI-STRAUSS, Claude. 1990. De perto e De Longe. Rio de Janeiro: Nova Fronteira.

FAUSTO, Carlos. 2001. Inimigos Fiéis. Guerra e xamanismo na amazônia. São Paulo: Edusp.

GODELIER, Maurice. 1996. L’Enigma du Don. Paris: Librairie Arthème Fayard.

GODELIER, Maurice. \& STRATHERN, Marilyn. (eds.).1991. Big men and Great men: personifications of power in Melanesia. Cambridge: Cambridge University Press.

GRAEBER, David, \& LANNA, Marcos. 2005. "Comunismo ou comunalismo? A política e o 'Ensaio sobre o dom”. Revista de Antropologia, 48(2), 501-523. São Paulo: USP.

LANNA, Marcos. 2013. "Marx's alienation and Mauss alienability: a contrast" paper apresentado no Simpósio "Beyond engagement", coordenado por Suzanne Oakdale, 112th American Anthropological Association Congress. 
LÉVI-STRAUSS, Claude. 1982 [1949]. As Estruturas Elementares do Parentesco. Petrópolis: Vozes.[Les Structures Élémentaires de la Parenté, Paris: PUF].

Structurale. Paris: Plon].

2008. [1958]. Antropologia Estrutural. São Paulo: Cosac \& Naify. [Anthropologie

Lévi-Strauss, Claude. 1962. Le Totémisme Aujourd'hui. Paris: PUF

Paris: Plon].

2008b [1962b]. O Pensamento Selvagem. Campinas: Papirus. [La Pensée Sauvage.

1989 [1973]. Antropologia Estrutural Dois. Rio de Janeiro: Tempo Brasileiro.

[Anthropologie Structurale Deux. Paris: Plon]

MALINOWSKI, Brosnilaw. 1930. "Kinship”. Man, Vol. 30 (Feb., 1930). London: The Royal Institute of Anthropology. pp. 19-29.

MARX, Karl. 1985. O Capital. Livro I, Vol. I. São Paulo: Abril Cultural.

Paulo: Paz e Terra.

1986. Formações Econômicas Pré-Capitalistas (com Introdução de Eric Hobsbawm). São

MARX, Karl e ENGELS, Friedrich. 1984. A Ideologia Alemã. São Paulo: Hucitec.

MEILLASSOUX, Claude. 1964. Anthropologie Économique des Gouro de Côte D'ivoire. De l'économie de subsistance à l'agriculture commerciale. Paris: Mouton.

MORGAN, Lewis H. 1871. Systems of Consanguinity and Affinity of the Human Family. New York: Smithsonian Institute.

1877. Ancient Society. New York: Henry Holt and Company.

SAHLINS, Marshall. 1958. Social Stratification in Polynesia. Monographs of the American Ethnological Society, 29. Seattle: University of Washington Press

1963. "Poor Man, Rich Man, Big Man, Chief; Political Types in Melanesia and Polynesia”, In: Comparative Studies in Society and History, vol. 5, No.3, pp.285-303, abril de 1963

N.J.: Prentice-Hall. 1968. Tribesman. Foundations of American Anthropology Series. Englewood Cliffs, 1976. Culture and Practical Reason. Chicago: University of Chicago Press. 1985. Islands of History. Chicago: University of Chicago Press.

STRATHERN, Marilyn. 1988. The Gender of the Gift. Cambridge: Cambridge University Press.

TURNER, Terry. 2009. “The Crisis of Late Structuralism. Perspectivism and animism: rethinking culture, nature, spirit and bodiliness". Tipití: Journal of the Society for the Anthropology of Lowland South America. $\operatorname{Vol} 7$ (1). 
VIVEIROS DE CASTRO, Eduardo. 1999. “Etnologia Brasileira”. In Sérgio Miceli (org.). O que Ler na Ciência Social Brasileira: antropologia. São Paulo: Anpocs.

WEINER, Annette. 1992. Inalienable possessions: the paradox of keeping-while-giving. Berkeley: University of California Press. 